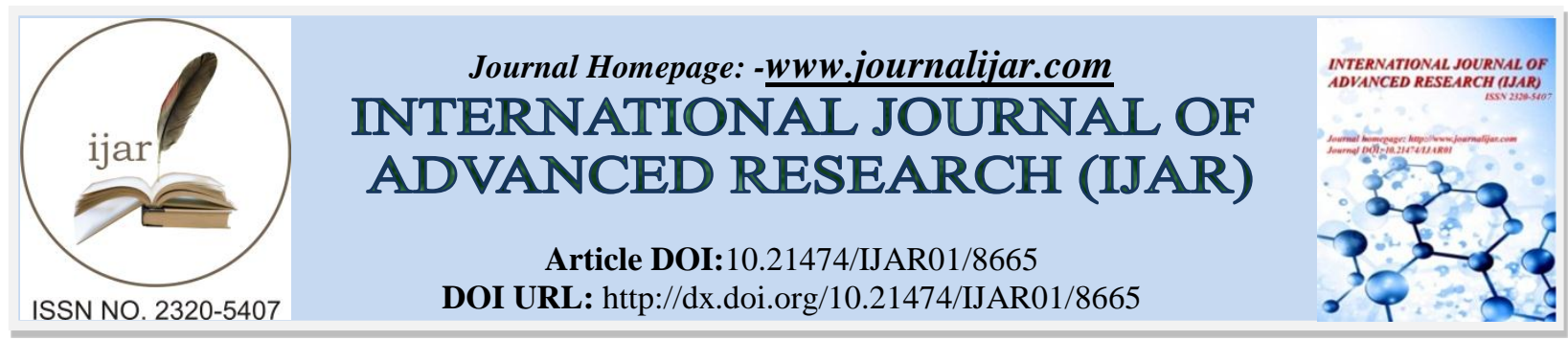

RESEARCH ARTICLE

\title{
HEALTH FACILITY FACTORS AND INDIVIDUAL FACTORS AS PREDICTORS OF UPTAKE OF SKILLED BIRTH SERVICES IN LURAMBI SUB COUNTY, KENYA.
}

Victor Emali Mukaka ${ }^{1}$ and Beatrice Mukabana ${ }^{2}$.

1. Department of Clinical nursing and health informatics, Masinde Muliro University of science and technology.

2. Department of Reproductive Health, Masinde Muliro University of science and technology.

\section{Manuscript Info}

Manuscript History

Received: 10 January 2019

Final Accepted: 12 February 2019

Published: March 2019

Key words:-

ANC, skilled birth delivery, Kakamega county, individual factors, health facility related factors, nursing.

\section{Abstract}

Introduction: Factors determining maternity services utilization are diverse and yet interrelated. They can be grouped into five main factors namely socio cultural factors, Physical access, and economic access, past obstetric experience and perceived benefit or quality of care.

Objective: To determine predictors of uptake of skilled birth services in Lurambi sub-County.

Methodology: A descriptive cross-sectional study adopting Quantitative methods. The study was carried out in Kakamega County and Sampling frame consisting of all the 17 government facilities were used. A multistage stratified sampling strategy was used and Probability sampling technique of systematic sampling applied to select women seeking health facility delivery services in Lurambi sub county government facilities $(n=200)$. Data was analyzed through descriptive statistics, chi-square test and logistic regression.

Results: The majority of the women were aged $20-35$ years $(70.5 \%)$ and $66 \%$ were married. About $40 \%$ had 1-2 children and majority had attained secondary education at $48.5 \%$ as the highest educational level. A majority of the women were business people at $25.5 \%$ and CHVs have a bigger role in deciding where the mothers deliver at $42 \%$. Majority of the mothers $77.5 \%$ were less wealthy and a majority of them attended the ANC clinic at $98.5 \%$. Chi square analysis showed that there was no statistically significant relationship between the skilled service delivery and age $\mathrm{X} 2(1, \mathrm{~N}=200)=0.22, \mathrm{p}>0.05$. Multinomial logistic regression was done, and the results showed people with one to two children were 1.7 times more likely $(\mathrm{OR}=1.17$, 95\% C.I, 0.4-3.8) to belong to the 'poor birth service' group than the 'good birth service' group compared to respondents who had seven children and above. With regards to marital status, respondents who were divorced from their spouses received good birth services (66.7\%), while majority of the married people received poor birth services (55.6\%). Results from chi square test showed that there was a statistically significant relationship between marital status and uptake of skilled birth service X2 $(4, \mathrm{~N}=248)=39.109, \mathrm{p}<0.05$. Bivariate analysis on health facility related factors that are associated with uptake of skilled service delivery showed that there was a borderline 
significant relationship between delivery place and uptake of skilled birth service in the study area (OR: $0.8 ; 95 \%$ CI: $0.6-1.2 ; \mathrm{p}=0.02$ )

Conclusion and Recommendation: Demographic factors like age, marital status, number of children and education level determine whether a woman would deliver in hospital or not.The factors are key players in women's ability to uptake skilled birth services. It is recommended that sensitization of the elderly women and adolescent girls be done on importance of early access of antenatal clinic and hospital delivery through the community health volunteers.

Copy Right, IJAR, 2019,. All rights reserved.

\section{Introduction:-}

Worldwide, a woman dies every minute from complications of pregnancy and childbirth. It is thus estimated that 1450 maternal deaths occur daily worldwide. In 2005, it was estimated that 536000 mothers died due to pregnancy related causes. Developing countries where most African countries fall accounted for $99 \%$ of the deaths. Approximately a half of the deaths 50.4\% (270 000) occurred in the sub-Saharan Africa region alone, followed by South Asia 35.1\% (188000). Thus, sub-Saharan Africa and South Asia accounted for 86\% of global maternal deaths (WHO, 2014). Factors determining maternity services utilization are diverse and yet interrelated. The factors can be grouped into five main factors namely socio cultural factors, Physical access, and economic access, past obstetric experience and perceived benefit or quality of care. Individual factors however are also shaped by other broader factors, often beyond the immediate control of the individual or community (Bourbonnais, 2013). According to Esena and Sappor (2013), some of the individual factors that have been linked to choice of place of delivery include infrastructure, household income, environmental factors and individual characteristics like parity, age, education and marital status.

Several studies that have been carried out to determine factors affecting utilization of skilled delivery services by analyzing demographic health surveys have come out with almost similar factors. Such is a study carried in Ghana which analyzed Ghana demographic health survey and in Kenya which analyzed Kenya demographic health survey 2008/2009 (Esena \& Sappor, 2013; Kitui et al., 2013. According to the studies some of the factors that increased utilization of delivery services included complications with previous pregnancy, health insurance coverage, socioeconomic status of the family and religion. The same studies also noted that living in urban areas, education, antenatal care services and low parity predicted the choice of place of birth by the women.

\section{Socio- economic factors}

Socio cultural contributors encompass both socio demographic factors and community factors that would hinder or facilitate use of these services. Gender autonomy also affects utilization of skilled delivery and determines the accessibility of the services. Maternal age, marriage status together with the woman's and spouse's level of formal education and the female gender access to and control of household income and resources are very critical (Muckle, Sprague, \& Fergus, 2013). The argument put forward is that persons with similar socio-economic characteristics may have different health seeking behavior depending on whether they live in one community or another and therefore the contextual phenomena that cluster individual health seeking behavior within communities has become a core notion of social epidemiology literature (Markos, et al, 2017). According to Muckle et al., (2013) one in three mothers in rural areas of Africa lives away from a health facility approximated at a distance of more than five kilometers from the nearest health facility. The scarcity of vehicles, in remote areas accompanied by poor road networks makes it very difficult for mothers to reach even relatively nearby facilities. Walking is the basic mode of transportation, even for mothers in labor. Muckel et al., (2013) also noted that in sub-Saharan Africa poor mothers in communities of high literacy are likely to utilize maternal health services than those who live in communities with lower education. In a study in Tanzania, poorer households in wealthy regions are found to be better off in maternal health care service utilization outcomes than poorer households in poorer regions (Markos, et al, 2017).

Hansford et al. (2014), noted that as much as women may own their own wealth in terms of land and even control their own income, most of them do not have an influence on their spouse's income. This puts the women in a vulnerable situation because they may not make independent decisions like spending money on healthcare services and taking an insurance cover which is an effective payment mechanism contributing to increase in utilization of 
maternal services in particular facility-based delivery. This is evident in most countries which have exemption programs for maternal health services (Hatt et al. 2013). The women utilize the services without any worries of settling down hospital bills.

\section{Health care factors}

Studies that have been done in most developing countries on utilization of maternal services have cited several reasons affecting utilization. Although many studies focus on factors surrounding health facilities like user fees, physical access distance and transport to the facility other confounding factors come in to play. This include socioeconomic factors like family economic status, education level for both women and their spouse and the decision of the women to utilize the services (Asule, 2017; Kitui, et al., 2013). According to studies carried out in most developing countries most women prefer home deliveries. The reason for this choice is perceived satisfaction with home deliveries by a traditional birth attendance who is said to be understanding and caring (Asule, 2017). A study by Sanghita, (2016) noted that there has been reports of mothers being treated unfairly in health facilities during birth. The unfair treatment include poor attitude by the health care providers and perceived poor quality of care.

According to Munabi-Babigumira et al. (2017), the care given to the mothers when they visit health facilities could be influenced by several factors. These include organization of the health facility, number of staff on duty availability of supplies and remuneration of the staff. Others include the team work that exist between the staff, how they communicate with the mothers and whether they are qualified to offer the services. Studies have shown that if a woman has a bad experience in a health facility or if she was disrespected she may never turn up to seek services any other time even if she so needs the services (Asule, 2017). Leberg et al. (2014) also noted that other factors related to the level of satisfaction with, or preference for home over facility deliveries include the distance of health facilities, fast access to traditional birth attendants and cost.

Esena and Sappor, (2013) in their study in Ghana noted that about $43 \%$ of participants did not use a health facility due to lack of transportation. The sentiment was echoed by Asule et.al.(2017) in their study on utilization of maternal services in a county referral hospital in Kenya. The use of antenatal services is linked to utilization of facility delivery and this is likely to be due to probably the health messages from the antenatal clinic which emphasizes the importance of facility delivery (Mehari, 2014). WHO recommends at list four antenatal visits for those women without complication. According to several studies factors that promote utilization include clean environment, positive attitude by the health workers, good infrastructure and proper waiting areas (Asule at el. ; UN, 2011) Other factors include good communication with the mothers, perceived satisfaction availability and quality of care. Safety and health of mother and child after delivery significantly influence a positive assessment of care by the mother (Sanghita, 2016).

Given that transport challenge is one of the factors that affect utilization of maternal services, construction of health facilities close to $2 \mathrm{~km}$ from the community is likely to improve utilization. Mwaliko et al. (2014) in his study confirmed that health facilities that were within $2 \mathrm{~km}$ from the respondent homes with EmOC services were more likely to be accessed. The same study recommended that some of the factors that were noted, when corrected could improve maternal services uptake. The factors included education levels for both mother and spouse, scaling up community -based Health Planning program and improving the existing infrastructure (Mwaliko et al. 2014; Adjei, 2015). These factors should be corrected in order to improve facility delivery. Facility delivery is a safe environment compared to home and this is likely to reduce neonatal deaths in low and middle income countries according to a systematic review carried out by Tura (Tura, 2013).

Most countries are working hard towards improving their health indicators but the high rates have remained persistent. According the studies carried out to find out why this is so, it was noted that the problem is driven partly due to lack of access to quality health care services and poor infrastructure (MOH, 2015). Therefore, the researcher found it necessary to conduct this study. The broad objective was to determine predictors of uptake of skilled birth services in Lurambi sub-County. The specific objectives were to determine the Individual factors influencing uptake of skilled birth services, to analyze health facility related factors that affecting uptake of skilled birth services in Lurambi sub-County. The findings will be utilized for planning and implementation of programs to improve uptake of skilled birth services in Lurambi sub-County. 


\section{Methods:-}

It was carried out in Kakamega county and ethics approval was sought from Masinde Muliro University of Science and Technology ethics board. No further approval was needed since the project did not require access to patients or personal data.

\section{Research Design}

Study design was quantitative design whereby the cross-sectional design was used due to time factor available for the study to be conducted hence requiring data to be collected in a point in time and secondly it was to facilitate the collection of original data necessary to realize the research objectives, and lastly it was appropriate in collecting useful data that was quantified and reported as a representation of the real situation or characteristic in the study population. It was a descriptive study that utilized cross section study design (Mugenda\& Mugenda, 2008). The descriptive survey was deemed the best strategy to fulfill the objectives of this study.

\section{Study setting and Participants}

Sampling frame consisting of all the 17 government facilities were used. A multistage stratified sampling strategy was used, since the facilities are not homogenous in terms of services offered. They were grouped into three strata which are homogenous in themselves i.e. those offering comprehensive emergency obstetric and neonatal care (CEmONC), those offering basic emergency obstetric and neonatal care (BEmONC) as health centres and as dispensaries. At each of the drawn facilities, three departments. MCH/FP, labour ward and maternity will be put into consideration and sample apportioned equally to the three departments as follows.

Table 1:-Sampling frame

\begin{tabular}{|c|c|c|c|}
\hline STRATA & $\begin{array}{ll}\text { NUMBER } & \text { OF } \\
\text { FACILITIES } & \end{array}$ & SAMPLE SIZE & $\begin{array}{l}\text { SAMPLE SIZE PER } \\
\text { FACILITY }\end{array}$ \\
\hline CEmONC- $50 \%$ & 1 & 103 & 103 \\
\hline BEmONC-Health centres-30\% & 2 & 62 & 31 \\
\hline BEmONC-Dispensaries-20\% & 14 & 41 & 3 \\
\hline Total & 17 & 206 & \\
\hline
\end{tabular}

Probability sampling technique of systematic sampling method was applied to select women seeking health facility delivery services in Lurambi sub county government facilities.

The study populations were women of reproductive age who have had a delivery in the past 6 months and seeking health facility delivery services at government health facilities in Lurambi Sub County. Study population was women of reproductive age of 15-49 years seeking delivery health services at government health facilities in Lurambi sub-county. All participants were women of reproductive age who had delivered in the past 6 months seeking delivery services at Lurambi sub-county government health facilities at the time of data collection. All otherwise were be excluded from the study. Using national prevalence of hospital delivery as $61 \%$ (KDHS, 2014), sample size calculated using the Fisher's method formula:

$$
\mathrm{n}=\frac{\mathrm{z}^{2} \times \mathrm{p}(1-\mathrm{p})}{2}
$$

Where $\mathrm{n}=$ minimum sample size

$\mathrm{z}=$ standard normal deviant at $95 \%$ confidence level (1.96)

$\mathrm{p}=$ prevalence i.e. $61 \%(0.61)$

$\mathrm{d}=$ margin of error of $5 \%(0.05)$

$$
\frac{1.962 \times 0.61(1-0.61)}{0.0025}=187
$$

$\mathrm{N}=187$

\section{$10 \%$ for non-response added to give us 206 respondents}

Informed and voluntary Consent was obtained from the participants before participation in the study to allow for their freedom in participation. Confidentiality was maintained at all levels for the data and information obtained by ensuring no names included in the questionnaires. Privacy for the participants was ensured through anonymity by 
ensuring no names appear on the questionnaires and that information does not identify directly to an individual. There was protection of the individuals from harassment, harm, discomfort or distress.

\section{Questionnaire}

Questionnaires were selected as data collection instruments. A questionnaire is a printed self-report from designed to elicit information that can be obtained through the written responses of subjects. The information obtained through a questionnaire is similar to that obtained by an interview, but questions to have less depth (Denzin, 1970). The instrument comprised of the following sections: In section one, questions sought to determine individual factors influencing uptake of skilled birth. In section two, questions sought to determine health facility factors influencing uptake of skilled birth. The questions were ranked on a dichotomous scale with the anchors being $\mathrm{No}=0$ to yes $=1$. To increase the validity and reliability of the instruments, the questionnaire was evaluated by experts. The reliability of the scale of the items was found to be: Internal consistency $=($ Cronbach's $\alpha=0.73)$. The analysis showed that deleting selected items would not increase the Cronbach's alpha coefficient.

\section{Procedures and data Analysis}

Each question was coded and entered in SPSS version 25.0. They were screened each question at a time, starting with first to last questionnaire. Data analysis was done using the statistical program for social sciences (SPSS) version 25. Inferential and descriptive statistics were used to analyze data. Descriptive analysis of data was done using measures of central tendency. In this study association between the study variables was assessed by a twotailed probability value of $\mathrm{p}<0.05$ which was considered significance. The researcher utilized Little's MCAR test (Schlomer et al., 2010) which employs a chi-square statistical analysis and assumes the null hypothesis, that missing data is missing completely due to randomness. Failing to reject the null hypothesis indicated that the data was most likely not missing in a random way. For this study, Little's MCAR test results showed that individual factors $\left(\chi^{2}\right.$ $[242]=96.447, \mathrm{p}=.695)$ was not significant indicating that the variables were missing completely at random, the researcher proceeded to address the missing data. The missing data items were imputed using the ExpectationMaximization (EM) algorithm within SPSS 25. Analyses of normality was conducted for the outcome variable, prior to hypothesis testing by examining kurtosis and skewness of the data. Elimination of observed outliers was based on a case by case basis, dependent on standard deviations, and on normality and homogeneity of variance assessments. Normality was assessed using examination of the histograms by seeing how they related or deviate against a normal bell curve distribution and observing the levels of kurtosis and skewness present.

To describe the distribution of each variables in the study univariate analysis was done and Bivariate analysis was done to investigate the strength of the association and check differences between the outcome variable and other independent variables. One-way analysis of variance (ANOVA) at 0.05 level of significance was used to determine if there is differences in Knowledge among levels of the demographic characteristics. The knowledge questions were to be indexed for each respondent and an index score was to be computed and was recorded on a new variable.

\section{Results:-}

Two hundred (200) questionnaires were filled and returned and this represented $97 \%$ response rate. According to Mugenda and Mugenda, (2003) this was very good responseTwo hundred (200) questionnaires were correctly filled and returned which represented a response rate of ninety-seven percent. According to Mugenda and Mugenda (2003) a response rate of 50 percent is adequate, a response rate of 60 percent is good, and a response rate of 70 percent is very good. While we should not expect full response in studies where responding is voluntary, scholars utilizing questionnaires should aim for a high response rate (Baruch \& Holtom, 2008). The study first asked the respondents to indicate their background characteristics based on the age-bracket, marital status, number of children and the level of education. The responses are given in a summarized form as below.is given in Table 2. 
Table 2:-Demographic Information

\begin{tabular}{|c|c|c|}
\hline & Number & Percent \\
\hline \multicolumn{3}{|l|}{ AGE } \\
\hline $10-14$ years & 5 & $2.50 \%$ \\
\hline $15-19$ years & 32 & $16 \%$ \\
\hline $20-35$ years & 141 & $70.50 \%$ \\
\hline $36-49$ years & 22 & $11 \%$ \\
\hline \multicolumn{3}{|l|}{ MARITAL STATUS } \\
\hline Married & 132 & $66 \%$ \\
\hline Singles & 37 & $18.50 \%$ \\
\hline Divorced & 3 & $1.50 \%$ \\
\hline Widowed & 15 & $7.50 \%$ \\
\hline Separated & 13 & $6.50 \%$ \\
\hline \multicolumn{3}{|c|}{ NUMBER OF CHULDREN } \\
\hline one to two & 80 & $40 \%$ \\
\hline Three to Four & 66 & $33 \%$ \\
\hline Five to Six & 45 & $22.50 \%$ \\
\hline Seven and above & 9 & $4.50 \%$ \\
\hline \multicolumn{3}{|c|}{ EDUCATION AL LEVEL } \\
\hline Primary & 49 & $24.50 \%$ \\
\hline Secondary & 97 & $48.50 \%$ \\
\hline College/University & 52 & $26 \%$ \\
\hline None & 2 & $1 \%$ \\
\hline
\end{tabular}

It can be deduced from the above table that majority of the women are aged 20-35\% (70.5\%), are married (66\%), have 1-2 children (40\%) and majority have attained secondary education at $48.5 \%$ as the highest educational level.

\section{Socio-economic factors}

In figure 2 the results shows that majority of the women are business people $(25.5 \%)$, followed by farmers $(21 \%)$, housewives $(21 \%)$ students (20\%),teachers (15\%) and least are medical personel (3.5\%).

From figure 3 it can be deduced that $\mathrm{CHVs}$ have a bigger role in deciding where the mothers deliver at $42 \%$, followed by own choice (27.5\%), decision with partner $(20.5 \%)$, partner's own decision $(9 \%)$ and lastly decision with the family members $(1 \%)$.

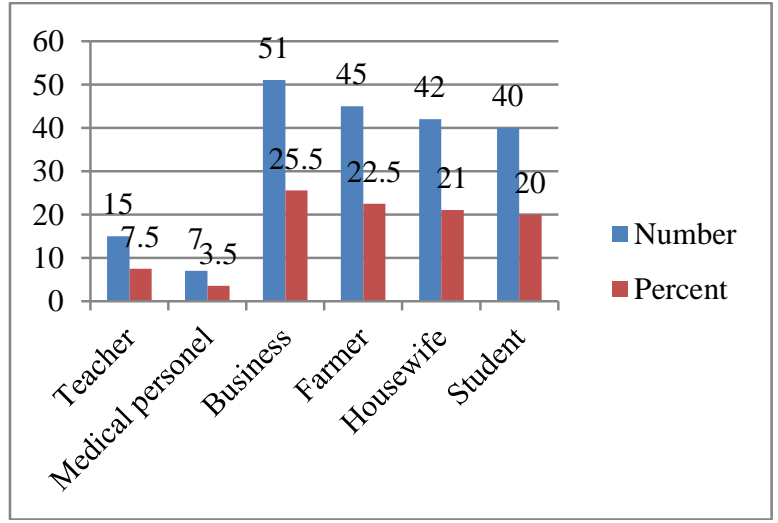

Figure 2:-Occupation

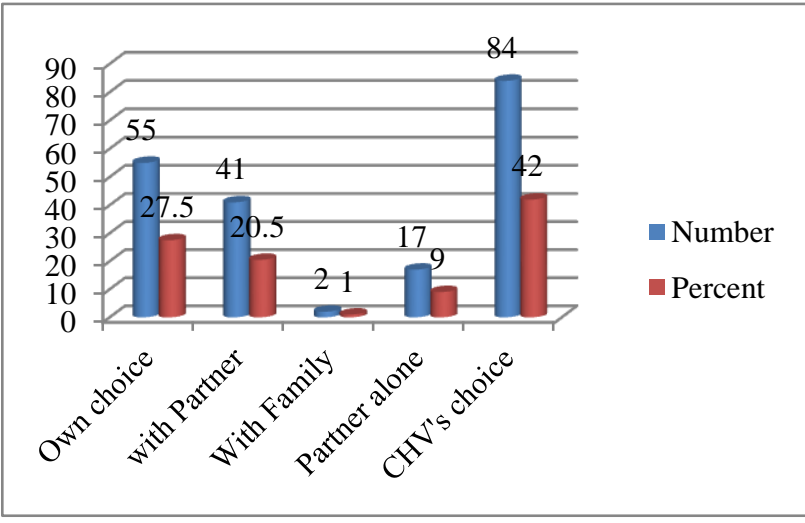

Figure 1:-Influence of women's decision on delivery at health facility 


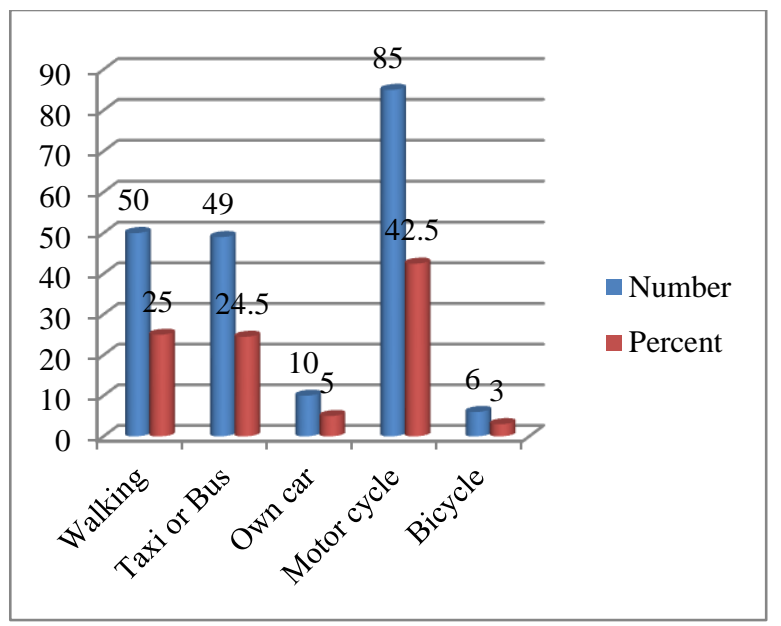

Figure 3:-Means of transportation to delivery venue

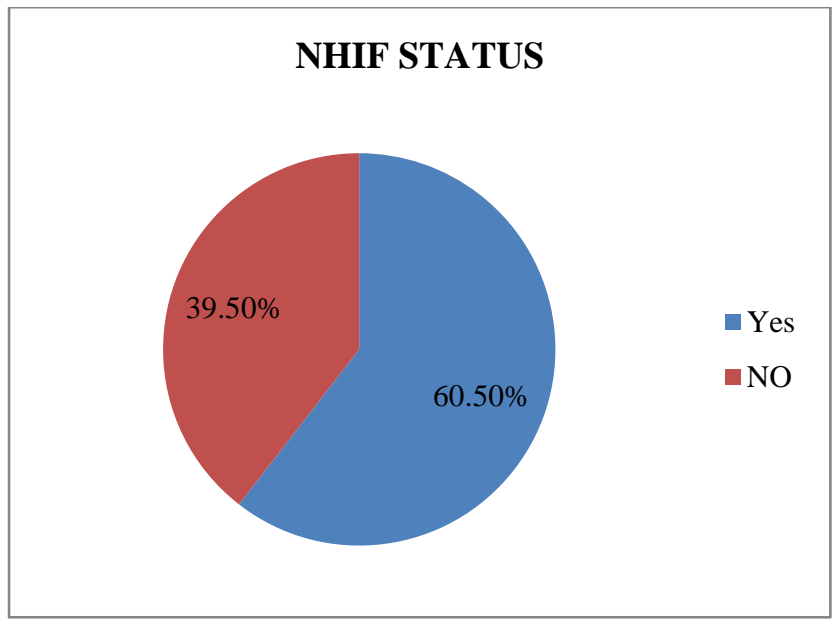

Figure 4:-NHIF holder

Figure 4 indicates that means of reaching the facility for delivery by most mothers is by motor cycle at $42.2 \%$ (85), followed by walking at $25 \%$ (50), then by taxi or bus at $24.5 \%$ (49), only $5 \%$ travel by own car and lastly $6 \%$ (3) travelled by bicycle. From figure 5 majority of the mothers are covered by NHIF at $60.5 \%$ and $39.5 \%$ are not covered by NHIF. Majority of the mothers are less wealthy as revealed in figure 6 at $77.5 \%$, the wealthy are at $22 \%$ and only $0.5 \%$ are wealthier. 


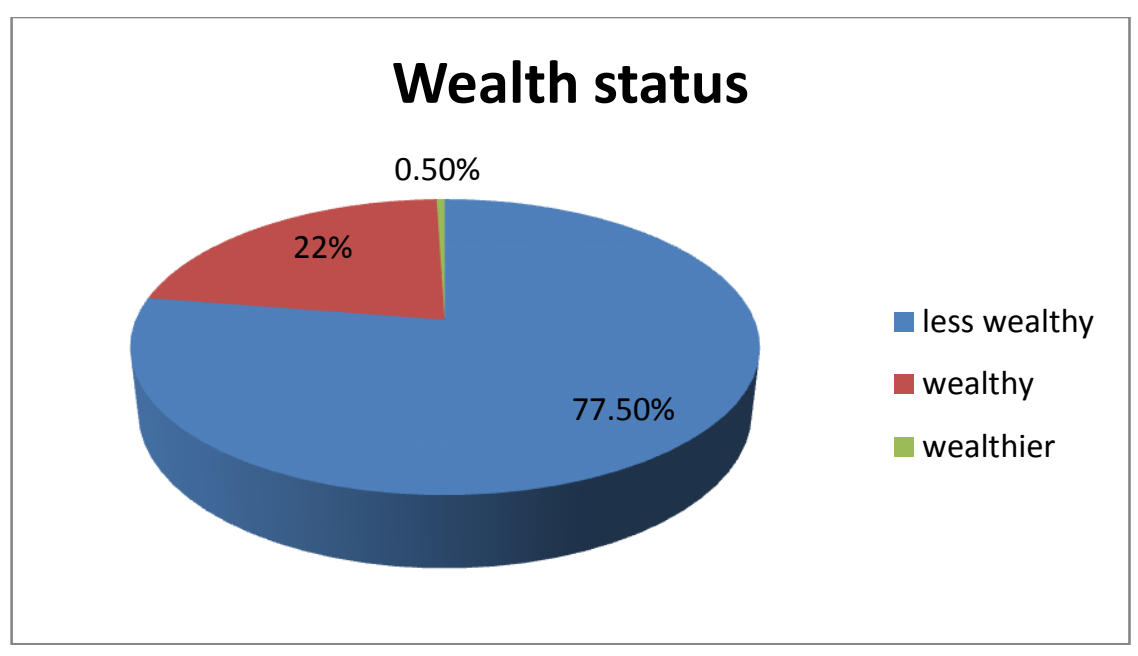

Figure 5:-wealth status classification

\section{Health care factors}

Majority of the mothers attended the ANC clinic at $98.5 \%$ and only $1.5 \%$ did not attend the ANC clinic. From figure 8 , it was deduced that majority of the women reside near health facilities at a distance of $1-5 \mathrm{~km}(94.5 \%)$ while only $5.5 \%$ travel far distance of $6 \mathrm{~km}$ and above to reach the facilities. From figure 9 it was noted that majority of the deliveries did occur in the health facility at $79.5 \%$ (159), while home deliveries were $12.5 \%$ (25) and $8 \%$ (16) delivered on the way to hospital. From figure 10 majority of the family members of the mothers seek medical services at government health facilities at $69 \%$ (138), followed by private facilities at $27.5 \%$ (55), then at traditional healers at $2.5 \%(5)$ and lastly at religious healers at $1 \%(2)$.

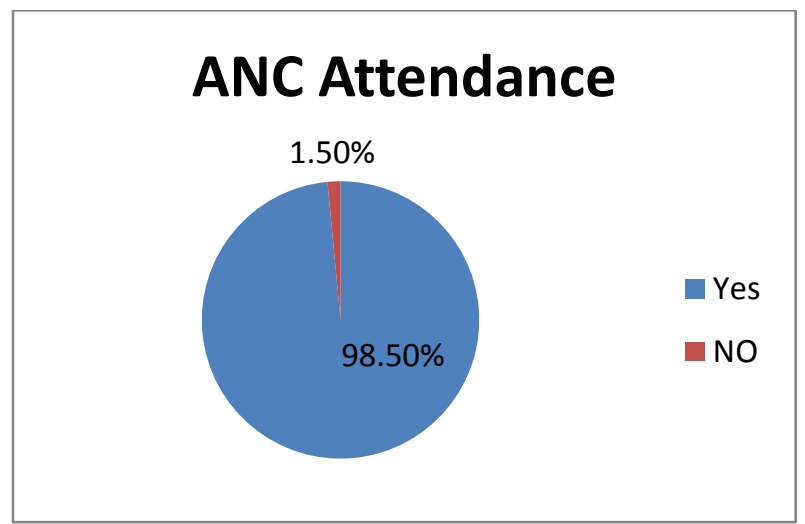

Figure 7:-ANC Attendance

\section{Distance to Facility in Kilometers}

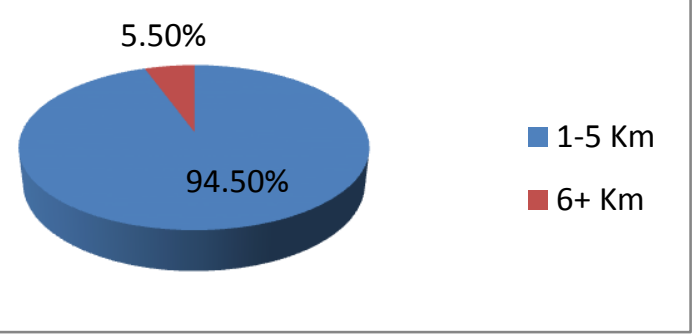

Figure 6:-Distance to health facility in kilometers 


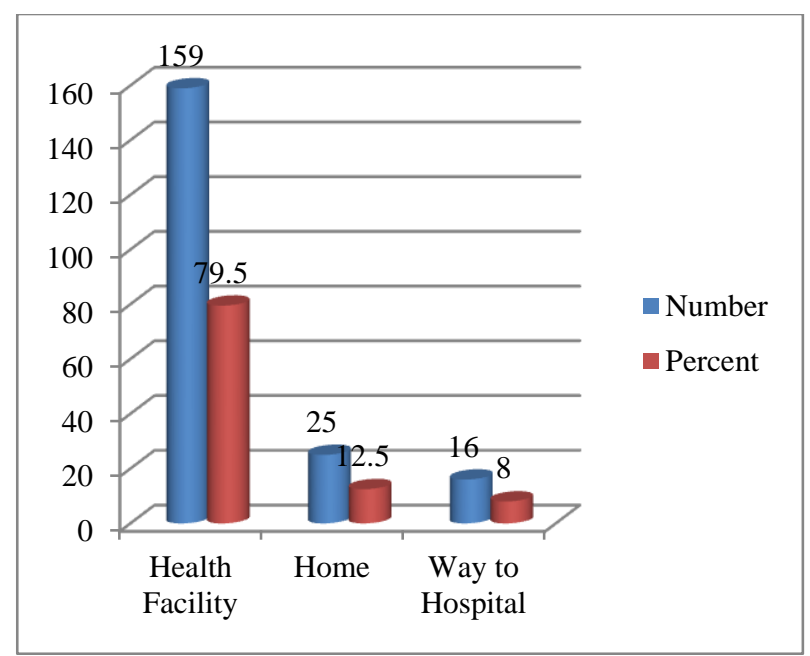

Figure 8:- Delivery place

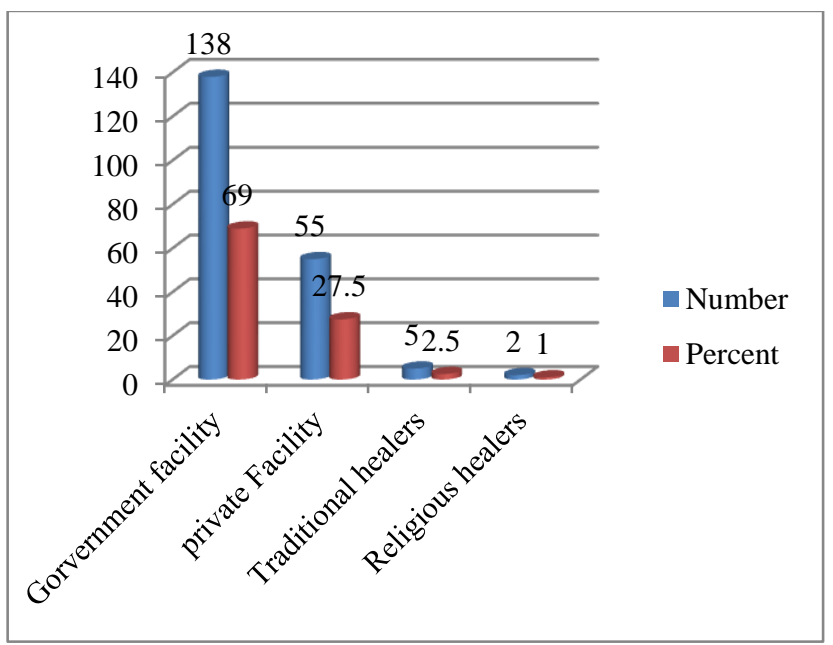

Figure 9:-Where family members seek medical services

In table 3 it was observed that majority of the women only attended the ANC clinic twice at $36 \%$ (72), followed by four visits and above at $31.5 \%$ (63), 3 visits were $23 \%$ (46), $8 \%$ (16) only attended the clinic once while $1.5 \%$ (3) did not attend the clinic at all.

Table 3:-Number of ANC clinic attendance

\begin{tabular}{|l|r|r|}
\hline ANC VISITS & Number & percent \\
\hline Once & 16 & $8 \%$ \\
\hline Twice & 72 & $36 \%$ \\
\hline Thrice & 46 & $23 \%$ \\
\hline Four and above & 63 & $31.50 \%$ \\
\hline Not applicable & 3 & $1.50 \%$ \\
\hline TOTAL & $\mathbf{2 0 0}$ & $\mathbf{1 0 0 \%}$ \\
\hline
\end{tabular}


In table 4 the results shows that majority of the mothers were delivered by the nurse/midwife at $77.5 \%$ (155), followed by traditional birth attendants at $10 \%(20)$, then by relatives at $5.5 \%(11)$, then by community health volunteers at $5 \%$ (10) and lastly by the doctor $2 \%(4)$.

Table 4:-Who assisted to deliver

\begin{tabular}{|l|r|r|}
\hline & Number & Percent \\
\hline Doctor & 4 & 2 \\
\hline Nurse/Midwife & 155 & 77.5 \\
\hline Community Health Volunteer & 10 & 5 \\
\hline Traditional Birth Attendant & 20 & 10 \\
\hline Relatives & 11 & 5.5 \\
\hline
\end{tabular}

Bivariate analysis of the relationship between individual factors and uptake of skilled birth service Results from table 5 show that the poor birth service among females of age 19 and below was higher $51.2 \%$ compared to those of age bracket 20 and above (48.8\%). However, chi square analysis showed that the relationship between the skilled service delivery and age was not statistically significant $X^{2}(1, N=200)=0.22, p>0.05$. Respondents who had five to six children received better birth service (72.7\%). Results from the chi square showed that there was a statistically significant relationship between number of children and uptake of skilled service delivery $\mathrm{X}^{2}(3, \mathrm{~N}=200)=32.722, \mathrm{p}<0.05$.

Multinomial logistic regression was done, and the results showed people with one to two children were 1.7 times more likely $(\mathrm{OR}=1.17,95 \%$ C.I, 0.4-3.8) to belong to the 'poor birth service' group than the 'good birth service' group compared to respondents who had seven children and above. With regards to marital status, respondents who were divorced from their spouses received good birth services (66.7\%), while majority of the married people received poor birth services $(55.6 \%)$. Results from chi square test showed that there was a statistically significant relationship between marital status and uptake of skilled birth service $X^{2}(4, N=248)=39.109, p<0.05$.

According to the Logistic regression that was done, respondents who were married were 0.4 times more likely $(\mathrm{OR}=0.42,95 \%$ C.I, 0.06-2.84) to belong to the 'poor birth service 'group than the 'good service' group compared to the separated. Table 5 is a bivariate analysis of individual factors and uptake of skilled birth service.

Table 5:-Bivariate analysis of Individual factors and skilled birth service

\begin{tabular}{|c|c|c|c|c|c|}
\hline & Totals & $\begin{array}{l}\text { Poor birth } \\
\text { service }(60 \%>)\end{array}$ & $\begin{array}{l}\text { Good birth service } \\
(60 \%<)\end{array}$ & O.R(95\% C.I) & $\chi^{2}(\mathbf{p}$ value $)$ \\
\hline \multicolumn{5}{|c|}{ Age Bracket } & 0.882 \\
\hline 19 and below & 37 & $51.2 \%$ & $48.8 \%$ & $1.34(1.1-1.8)$ & \\
\hline 20 and above & 163 & $47.3 \%$ & $52.7 \%$ & - & \\
\hline \multicolumn{5}{|c|}{ Number of Children } & 0.001 \\
\hline One to two & 80 & $46.9 \%$ & $53.1 \%$ & $1.171(0.359-3.825)$ & \\
\hline Three to four & 66 & $61.3 \%$ & $38.7 \%$ & $2.098(0.636-6.920)$ & \\
\hline Five to six & 45 & $27.3 \%$ & $72.7 \%$ & $0.110(0.022-0.544)$ & \\
\hline $\begin{array}{l}\text { Seven and } \\
\text { above }\end{array}$ & 9 & $50 \%$ & $50 \%$ & $*$ & \\
\hline \multicolumn{5}{|c|}{ Marital Status } & 0.05 \\
\hline Married & 132 & $55.6 \%$ & $44.4 \%$ & $0.419(0.062-2.835)$ & \\
\hline Single & 37 & $43.4 \%$ & $56.6 \%$ & $0.209(0.33-1.344)$ & \\
\hline Divorced & 3 & $33.3 \%$ & $66.7 \%$ & $0.500(0.05-4.957)$ & \\
\hline Widowed & 15 & $50 \%$ & $50 \%$ & $*$ & \\
\hline Separated & 13 & & & & \\
\hline \multicolumn{5}{|c|}{ Educational Level } & 0.069 \\
\hline $\begin{array}{l}\text { Primary } \\
\text { Education }\end{array}$ & 49 & $54.7 \%$ & $45.3 \%$ & & \\
\hline Secondary & 97 & $40 \%$ & $60 \%$ & & \\
\hline
\end{tabular}




\begin{tabular}{|l|l|l|l|l|l|}
\hline Education & & & & \\
\hline College & 52 & $42.9 \%$ & $50 \%$ & & \\
\hline *Reference category
\end{tabular}

Facility factors and uptake of skilled birth service

Table 6 is a bivariate analysis of facility related factors and uptake of skilled birth services. The proportion of those attending ANC receiving good birth service was higher (55.3\%) compared to those women who did not attend. The proportion of respondents receiving good birth service was higher in those who had attended ANC clinic thrice and below. The proportion of those travelling $6 \mathrm{~km}$ and above getting good birth service was higher (57\%) compared to those who travelled $1-5 \mathrm{~km}$.

Table 6:-Facility factors associated with uptake of skilled birth service

\begin{tabular}{|c|c|c|c|c|c|c|c|}
\hline \multirow[t]{2}{*}{ Characteristic } & \multirow[b]{2}{*}{$\mathbf{N}$} & \multicolumn{2}{|c|}{ Skilled birth service } & \multirow[t]{2}{*}{ Overall OR } & \multirow{2}{*}{\multicolumn{2}{|c|}{$\begin{array}{l}95 \% \\
\text { CI }\end{array}$}} & \multirow[t]{2}{*}{$p$ value } \\
\hline & & Good service & Poor services & & & & \\
\hline \multicolumn{8}{|l|}{ ANC attendance } \\
\hline Yes & 197 & 55.3 & 44.7 & \multirow[t]{2}{*}{1.1} & \multirow{2}{*}{\multicolumn{2}{|c|}{$\begin{array}{l}0.7 \\
1.5\end{array}$}} & \multirow[t]{2}{*}{0.7} \\
\hline No & 3 & 53.8 & 46.2 & & & & \\
\hline \multicolumn{8}{|l|}{ ANC clinics } \\
\hline Thrice and below & 134 & 54.7 & 45.3 & \multirow[t]{2}{*}{1.3} & \multirow{2}{*}{\multicolumn{2}{|c|}{$\begin{array}{l}0.7 \\
2.3\end{array}$}} & \multirow[t]{2}{*}{0.01} \\
\hline Four and above & 66 & 47.9 & 52.1 & & & & \\
\hline \multicolumn{8}{|l|}{ Distance } \\
\hline $1-5 \mathrm{~km}$ & 189 & 47.9 & 52.1 & \multirow[t]{2}{*}{0.7} & \multirow{2}{*}{\multicolumn{2}{|c|}{$\begin{array}{l}0.5 \\
1.0\end{array}$}} & \multirow[t]{2}{*}{0.06} \\
\hline $6 \mathrm{~km}$ and above & 11 & 56.6 & 43.4 & & & & \\
\hline \multicolumn{8}{|l|}{ Delivery place } \\
\hline Health facility & 159 & 50.6 & 49.4 & \multirow[t]{2}{*}{0.8} & \multirow{2}{*}{\multicolumn{2}{|c|}{$\begin{array}{l}0.6 \\
1.2\end{array}$}} & \multirow[t]{2}{*}{0.02} \\
\hline Home & 41 & 55.6 & 44.4 & & & & \\
\hline \multicolumn{8}{|l|}{ Assisted delivery } \\
\hline Doctor/nurse & 159 & 58.2 & 41.8 & \multirow[t]{2}{*}{1.6} & \multirow{2}{*}{\multicolumn{2}{|c|}{$\begin{array}{l}1.1 \\
2.2\end{array}$}} & \multirow[t]{2}{*}{0.01} \\
\hline Others & 41 & 47.2 & 52.8 & & & & \\
\hline \multicolumn{8}{|c|}{$\begin{array}{l}\text { Family seeks medicals } \\
\text { services }\end{array}$} \\
\hline Hospital & 193 & 57.0 & 43.0 & \multirow[t]{2}{*}{2.0} & \multirow{2}{*}{\multicolumn{2}{|c|}{$\begin{array}{l}1.3 \\
3.2\end{array}$}} & \multirow[t]{2}{*}{0.002} \\
\hline Elsewhere & 7 & 39.6 & 60.4 & & & & \\
\hline
\end{tabular}

According to the Bivariate analysis the factors that were associated with utilization of maternal services showed that there was some significant relationship between the place of delivery and utilization of maternal services (OR: 0.8; 95\% CI: $0.6-1.2 ; \mathrm{p}=0.02)$. The women who had a birth under skilled attendant were one and a half more likely to have good outcomes than those who did not i.e those who were assisted by other people (OR: 1.6; $95 \%$ CI: 1.1 2.2; $\mathrm{p}=0.01$ ). The number of ANC clinics attended was statistically significant with uptake of skilled birth services, with the results showing that respondents who attended ANC thrice or below were one point three times more likely to receive good birth service compared to respondents who attended ANC four times and above (OR: $1.395 \%$ CI: $0.7-2.3 ; \mathrm{p}=0.01)$. Similarly, respondents who sought medical services from hospital were about two times more likely to get better birth services in contrast to those who sought medical services elsewhere (OR: 2.0; $95 \% \mathrm{CI}$ : $1.3-$ $3.2 ; \mathrm{p}=0.002)$.

\section{Discussion:-}

The study had two specific objectives which were to determine the Individual factors that influence uptake of skilled birth services and to analyze health facility related factors that affect uptake of skilled birth services in Lurambi subCounty. The study notedd that demographic factors highly influenced the uptake of skilled delivery as evidenced in table 2 where majority of the women who seek skilled delivery are aged 20-35 years (70.5\%) and are married (66\%) have 1-2 children (40\%) and majority have attained secondary education at $48.5 \%$ (table 2), this is in agreement with Various studies which have demonstrated that the influences of parity on women's choice of place of birth (Moyer et al., 2013; Tey \& Lai., 2013).The fewer uptakes of institutional delivery services by multiparous women has been linked to perceived maternity experience coupled with high confidence of these women (Tey \& Lai 2013). 
A study done in the Ga East Municipality of Ghana to identify barriers to utilization of skilled delivery services noted that there was no associations between women marital status at birth and the utilization of skilled delivery services (Esena \& Sappor, 2013),. This though is contrary to the findings in the study which as demonstrated in table 2 noted that majority of the women who delivered in the health facility were married.

A study carried out in Kenya demonstrated less use of maternity services among women who were single, widowed or in polygamous relationship (Byford-Richardson et al. 2013). In other studied women's educational level has been shown as an important predictor for utilization of skilled delivery service (Moyer \& Mustafa 2013).The findings in this study are in agreement with the findings which reveal that majority of the women who delivered in the health facility had attained secondary education and above (table 2). The study therefore concluded that women who are well educated are more likely to deliver in health facilities than their counterparts who have low level of education or those with no formal education (Esena \& Sappor 2013).

The findings also revealed that the socio-economic status of the women predicted whether the women will use health facility for delivery or not (figure 2, 3,4,5 \& 6), this though is well known to be dependent on one's position in the wealth hierarchy (Exavery 2014). Economic status of women is reported in many studies to have significant effects on the use of skilled delivery service (Moyer \& Mustafa 2013) and some linkage has also been established with respect to women autonomy and utilization of skilled delivery services (Byford Richardson et al., 2013; Moyer and Mustafa, 2013). Women who have freedom to make decisions pertaining to their health are more likely to utilize delivery services (Ononokpono \& Odimegwu 2013). These studies contradict the findings in this study which noted that the CHVs have a big effect on the women's influence on choice of place of delivery $44.5 \%$ (figure 3 ).

The results shows that most of the women had Linda mama NHIF cover and this greatly impacted on the increased uptake of skilled delivery (figure 5), and majority pointed out the importance of the Linda mama card, which has been adopted in Kenya for all pregnant mothers. This is supported by (Hatt et al. 2013) who states that health insurance has been documented as one of the best payment mechanism that has contributed positively to utilization of facility-based delivery. Transportation challenges to a health facility which span from unavailability to affordability may influence the decision of women on the choice of place of birth (61.5\%) (Table 5). A study conducted in Ghana found that $43 \%$ of respondents who failed to use a health facility for delivery cited transportation challenges as reason (Esena \& Sappor 2013). Some of these challenges included high cost of transport and poor roads and lack of the vehicle. These findings are similar to other study findings carried out in African countries (Lerberg et al., 2014)

Distance to the facility was not a major hindrance factor to hospital as majority of the mothers were residing at a distance of 1-5km (94.5\%) (figure 8), as supported by Mwaliko et al. (2014) found that health facilities that were within $2 \mathrm{~km}$ from the respondent homes with EmOC services were more likely to be accessed. Higher number of women who attended the ANC clinic more than once did deliver in the health facility, hence association of the number of clinic attendance and health facility delivery uptake (table $3 \&$ figure 8 ). This is supported by (Mehari,2014) who stated that, Antenatal Care visit is found to be associated with the use of institutional delivery services and also act as a window for uptake of skilled birth attendance. A minimum of four ANC visits is recommended for every pregnant woman without complications (UN 2011) and Kenya has adopted this protocol.

\section{Conclusion:-}

The study concludes that demographic factors like age, marital status, number of children and education level determine whether a woman would deliver in hospital or not and that the adolescents aged 15-19 years and the elderly aged 35-49 years were most likely to attend only one clinic visit if not attend at all.

The economic status like being wealthy determined whether one would afford means of transport to the facility for delivery and those who attended the ANC visits more than once were likely to deliver in the hospital.

\section{Recommendation:-}

The researcher recommends that sensitization of the elderly women and adolescent girls be done on importance of early access of antenatal clinic and hospital delivery through the community health volunteers.

The county government should make access to health facilities easier to mothers by availing ambulance services to transport mothers from the community to the facility. 
The community to be sensitized to plan and have a community ambulance in which they own and can be sustained with the available resources.

\section{Declarations}

\section{Ethics Approval}

Ethical clearance was obtained from Masinde Muliro University of Science and Technology Ethics Committee. Consent and approval were also obtained from Kakamega county director of heath Chair of the identified health facilities and the local administration in each of the sub counties.

\section{Competing interest}

The authors declare that they have no competing interests.

\section{Authors\& contributions}

The two authors conceived, designed and performed the study. They also read and approved the final manuscript.

\section{Disclaimer}

The findings and conclusions presented in this manuscript are those of the authors and do not necessarily reflect the official position of Masinde Muliro University.

\section{Acknowledgements:-}

We are grateful to Micky Olutende Oloo who analyzed the data. We are also grateful to the health facilities and healthcare professionals who granted permission to participate in this study, the county government of Kakamega and the facility managers.

\section{Reference:-}

1. .Adjei,C.A.,(2015).Factors_influencing_uptake_of_institutional_delivery_service_by_skilled_birthattendant's_i n_ghana_review_of_literature. https://www.researchgate.net/publication/278036629 [accessed Aug 07 2018].

2. Asule, B. M., Kwena, A., \& Wambui, T. (2017). Effects of The Free Maternity Care Program on Utilization of Services at A County Referral Hospital in Kenya. Kenyan Journal Of Nursing \& Midwifery, 1(2).

3. Bourbonnais, N. (2013). Implementing Free Maternity Care in Kenya, Challenges, strategies and recommendation - KNCHR

4. Burns, H; \& Groove, S.K. (2011). Understanding nursing research: building on Evidence - based practice. $5^{\text {th }}$ ed. Arlington: Texas

5. Esena, R. K., \& Sappor, M. M. (2013). Factors Associated with the utilization of skilled delivery services in the Ga East Municipality of Ghana Part 2: Barriers to skilled delivery. Int J Sci Tech Res, 2(8), 195-207

6. Fisher, A. A., Laing, J.E., Stockel, E.J., and Townsend, J.W. (1998): Handbook for Family Planning operation research design 43-46. Population council $2^{\text {en }}$ eds: United States of America

7. Hansford, F., O., Anjorim, and Pittore K., (2014). Gender inequality and maternal and child nutrition in Northern Nigeria.

8. Hatt, LE, Makinen, M, Madhavan, S, Conlon, CM 2013, "Effects of User Fee Exemptions on the Provision and Use of Maternal Health Services: A Review of Literature" J HEALTH POPUL NUTR, vol. 31 no.4

9. Kitui J, Lewis S, Davey G. (2013). Factors influencing place of delivery for women in Kenya: an analysis of the Kenya demographic and health survey, 2008/2009. BMC Pregnancy Childbirth, 2013; 13: 40.

10. Lerberg, P. M., Sundby, J., Jammeh, A., \& Fretheim, A. (2014). Barriers to skilled birth attendance: a survey among mothers in rural Gambia. African journal of reproductive health, 18(1), 35-43.

11. Markos M., Gobopamang L., Kannan N., Hadgu B. (2017). Individual, household and contextual factors associated with skilled delivery care in Ethiopia: Evidence from Ethiopian demographic and health surveys. https://doi.org/10.1371/journal.pone.0184688

12. Ministry of Health, Health Sector Monitoring \& Evaluation Unit, (MOH), (2015). Status of program in the devolved health system in kenya. A Comprehensive Assessment Report. WHO and UKAID

13. Muckle, W., Sprague, A., \& Fergus, S. (2013). Barriers to access of maternity care in Kenya: a social perspective. J Obstet Gynaecol Can, 35(2), 125-130.

14. Mugenda, O. M. Mugenda, A.G. (2003). Research Methods, Qualitative and Quantitative Approaches. African Technology Studies Centre-Kampala. 
15. Munabi-Babigumira S, Glenton C, Lewin S, Fretheim A, Nabudere H (2017). What factors influence the delivery of care by skilled birth attendants in low- and middle-income countries? Cochrane.Published: 17November 2017.

16. Mwaliko, E, Downing, R, Wendy O'Meara, W, Chelagat, D, Andrew Obala, A, Downing, T, Simiyu, C, Odhiambo, D, Ayuo, P, Menya, D and Khwa-Otsyula, B 2014, "Not too far to walk: the influence of distance on place of delivery in a western Kenya health demographic surveillance system", BMC Health Services Research vol.14, no. 212

17. Ononokpono, DN, Odimegwu OC, (2013). "Determinants of Maternal Health care utilization in Nigeria: a multilevel approach", Pan Afr Med J. vol. 17, no. 2

18. Sanghita, B., Aradhana, S., Reetabrata, R., Bilal I. A. (2016). Factors influencing women's preference for health facility deliveries in Jharkhand state, India: a cross sectional analysis. BMC Pregnancy Childbirth. 2016; 16: 50. Published online 2016 Mar 7. doi: 10.1186/s12884-016-0839-6.

19. Schlomer, G. L., Bauman, S., \& Card, N. A. (2010). Best practices for missing data management in counseling psychology. Journal of Counseling Psychology, 57(1), 1-10. doi:10.1037/a0018082

20. Tey, NP, \& Lai, S., (2013, "Correlates of and barriers to the utilization of health services for delivery in South Asia and Sub-Saharan Africa", The Scientific World Journal vol. 2013

21. Tura, G, Fantahun, M, Worku, A 2013, "The effect of health facility delivery on neonatal mortality: systematic review and meta-analysis" BMC Pregnancy and Childbirth, vol. 13, no. 18

22. World Health Organisation. (2014). Reproductive health indicators: guidelines for their generation, interpretation and analysis for global monitoring. URL: www.who.int/reproductivehealth/publications/rh_indicators/. Accessed 28th Sept_2014. 